\title{
A Case of Restless Legs Syndrome in Patient with Neurogenic Sciatic Nerve Tumor
}

\author{
Ji Hoon Lee ${ }^{1}$, Kyoung Jin Hwang ${ }^{2}$, Sung Sang Yoon ${ }^{2}$, Key-Chung Park ${ }^{2}$, Jin San Lee \\ ${ }^{1}$ Department of Neurology, Kyung Hee University Hospital at Gangdong, Seoul, \\ ${ }^{2}$ Department of Neurology, Kyung Hee University Hospital, Seoul, Korea
}

궁둥신경의 신경성 종양으로 인한 하지불안증후군 1예

이지훈, 황경진 ${ }^{2}$, 윤성상 ${ }^{2}$, 박기정 ${ }^{2}$, 이진산 $^{2}$

강동경희대학교병원 신경과, ${ }^{1}$ 경희대학교병원 신경과 ${ }^{2}$

Received November 7, 2017

Revised November 30, 2017

Accepted December 4, 2017

Address for correspondence

Jin San Lee, MD

Department of Neurology,

Kyung Hee University Hospital,

23 Kyungheedae-ro,

Dongdaemun-gu, Seoul 02447,

Korea

Tel: +82-2-958-8499

Fax: +82-2-958-8490

E-mail: xpist@naver.com
Restless legs syndrome (RLS) is chronic neurological disorder, in which the primary symptoms is unpleasant and disturbing sensation accompanied by urge to move in multiple body parts especially in legs. RLS may present in distinct phenotypes often described as "primary" vs. "secondary." Secondary RLS can arise from etiologies such as iron deficiency, pregnancy, peripheral neuropathy, and end-stage renal disease. We report a rare case of RLS associated with neurogenic tumor of the sciatic nerve. A 72-year-old man complained of recurrent and worsening RLS symptoms in his right lower extremity, despite medical treatment. Interestingly, we found a neurogenic tumor at the right greater sciatic notch region on magnetic resonance imaging of the hip.

J Sleep Med 2017;14(2):74-76

Key Words: Restless leg syndrome, Sciatic nerve, Tumor. 하지불안증후군(restless legs syndrome)은 주로 하지에 이상감각과 함께 움직이고 싶은 충동이 나타나는 만성 신경 계 질환으로, 쉬거나 가만히 있으면 악화되었다가 움직이면 호전되며, 주로 저녁이나 밤에 악화되는 특징적인 양상을 보 인다. ${ }^{1}$ 국내 유병률은 0.9 12.1\%로 보고된 바 있으며, ${ }^{2}$ 연관 된 질환의 유무에 따라 원발성과 이차성으로 나눌 수 있다. 원발성 하지불안증후군은 보통 30세 이전에 발병하고 진행 이 느린 반면, 이차성 하지불안증후군은 비교적 고령에서 발 병하며 증상이 심하고 진행이 빠른 편으로 알려져 있다. ${ }^{3}$ 이 차성 하지불안증후군의 비교적 흔한 원인으로는 임신, 빈혈, 만성 신부전, 철결핍, 말초신경염, 그리고 류마티스관절염 등이 있고, 드물게 항히스타민제 또는 항우울제 등의 약물에 의한 원인 또한 보고된 바 있다. ${ }^{4}$ 저자들은 궁둥신경(sciatic nerve)의 신경성 종양이 원인으로 추청되는 하지불안증후군 의 드문 증례를 경험하였기에 문헌고찰과 함께 보고한다.

This is an Open Access article distributed under the terms of the Creative Commons Attribution Non-Commercial License (http://creativecommons.org/licenses/by-nc/4.0) which permits unrestricted non-commercial use, distribution, and reproduction in any medium, provided the original work is properly cited.

\section{증 례}

특별한 병력이 없는 72세 남성이 3개월 전부터 발생한 우 측 허벅지 감각저하로 내원하였다. 우측 허벅지 외측을 만졌 을 때 좌측의 동일 부위에 비해 감각이 떨어졌고, 간헐적으 로 오래 걷거나 서 있는 경우 같은 부위의 통증도 반복되었 다. 신경학적 검진에서 우측 외측넙다리피부신경(lateral femoral cutaneous nerve) 부위의 감각저하가 확인되었고, 그 외 심부건반사 이상이나 근력저하, 근위축 등 다른 신경학적 이상은 관찰되지 않았다. 신경전도검사에서는 우측 외측넙 다리피부신경의 감각신경활동전위의 진폭은 정상이었지만, 감각신경전도속도가 좌측에 비해 약 $20 \%$ 감소된 소견만이 관찰되었다. 이상의 소견으로 우측 외측넙다리피부신경병(lateral femoral cutaneous neuropathy, meralgia paresthetica) 을 진단하였고 약물치료(gabapentin $300 \mathrm{mg} / \mathrm{day}$ )를 하며 증 상은 호전되었다.

3 개월 뒤 환자는 이전과는 다른 우측 하지의 이상감각을 
호소하였다. 이는 주로 우측 무릎부터 원위부로, 종아리에서 발끝까지 '간지러운 느낌’ 혹은 ‘스멀거리는 느낌' 등의 복합 적인 이상감각이었으며 주로 잠자리에 들기 전 심하게 발생 하였다. 가만히 있을 때 이상감각과 동반하여 우측 하지를 움직이고 싶은 충동이 동반되었고, 움직이면 이상감각은 잠 시 소실되었으나 이내 곧 반복되는 증상으로 수면에 어려움 을 보였다. 외래에 내원하기 일주일 전부터는 수일에 한 번 꼴로 발생하던 증상이 매일 반복되고 있었다. 환자의 증상은 국제하지불안증후군 연구그룹에서 제시한 4가지 필수진단 기준을 만족하였다. 이차성 하지불안증후군의 원인 감별을 위한 혈액검사(혈색소, 평균적혈구용적, 혈청철, 혈중페리 틴, 갑상샘자극호르몬, 신기능검사, 당화혈색소)에서는 이상 소견이 보이지 않았고 가족력 또한 없었다. 임상적으로 하지 불안증후군을 진단하였고 ropinirole $0.25 \mathrm{mg}$ 을 취침 전 한 번 추가적으로 복용하도록 처방하였다. 이후 외래에서 추적 관찰하였을 때 환자의 증상은 크게 호전되었다.

약 1 년 후 환자의 증상은 빈도나 강도 면에서 이전보다 악 화되었다. 약물을 증량하여 ropinirole $0.5 \mathrm{mg}$ 과 gabapentin $300 \mathrm{mg}$ 을 취침 전 복용하도록 하였는데, 하지불안증후군 증 상이 약물치료에도 불구하고 시간이 지나며 악화되는 경과 를 보였기 때문에 이차성 하지불안증후군의 다른 원인을 찾
기 위하여 자기공명영상검사를 시행하였다. 고관절 자기공 명영상검사에서 우측 큰 궁둥패임(greater sciatic notch) 부 위를 주행하는 궁둥신경 주위에서 지름 $2.2 \mathrm{~cm}$ 의 결절형 덩 이가 관찰되었는데, 이는 T1 turbo spin echo 영상과 T2 spectral adiabatic inversion recovery 영상에서 나타나는 소견 을 종합하였을 때, 궁둥신경에서 기원한 신경성 종양(neurogenic tumor)의 가능성이 가장 높을 것으로 추측되었다(Fig. 1). 따라서 본 증례에서 보인 하지불안증후군의 원인을 궁둥신 경의 신경성 종양으로 인한 증상으로 판단하여 수술적 치료 까지 고려하였으나, 환자는 거부하였고 이후 외래 방문을 하 지 않았다.

\section{고 찰}

궁둥신경 종양은 드문 것으로 알려져 있는데 10 만 명당 0.6 명의 유병률이 보고된 바 있고, 양성 궁둥신경 종양의 약 $60 \%$ 가 신경섬유종(neurofibroma), 그리고 약 $38 \%$ 가 신경집종 (schwannoma)의 조직학적인 소견을 보이는 것으로 알려져 있다. ${ }^{5}$ 이는 주로 통증이나 저림 같은 감각증상을 보이는 경 우가 많지만, 천천히 자라는 경우에는 특별한 증상을 나타내 지 않아 진단이 어렵다. 또한 증상이 있더라도 좌골신경통
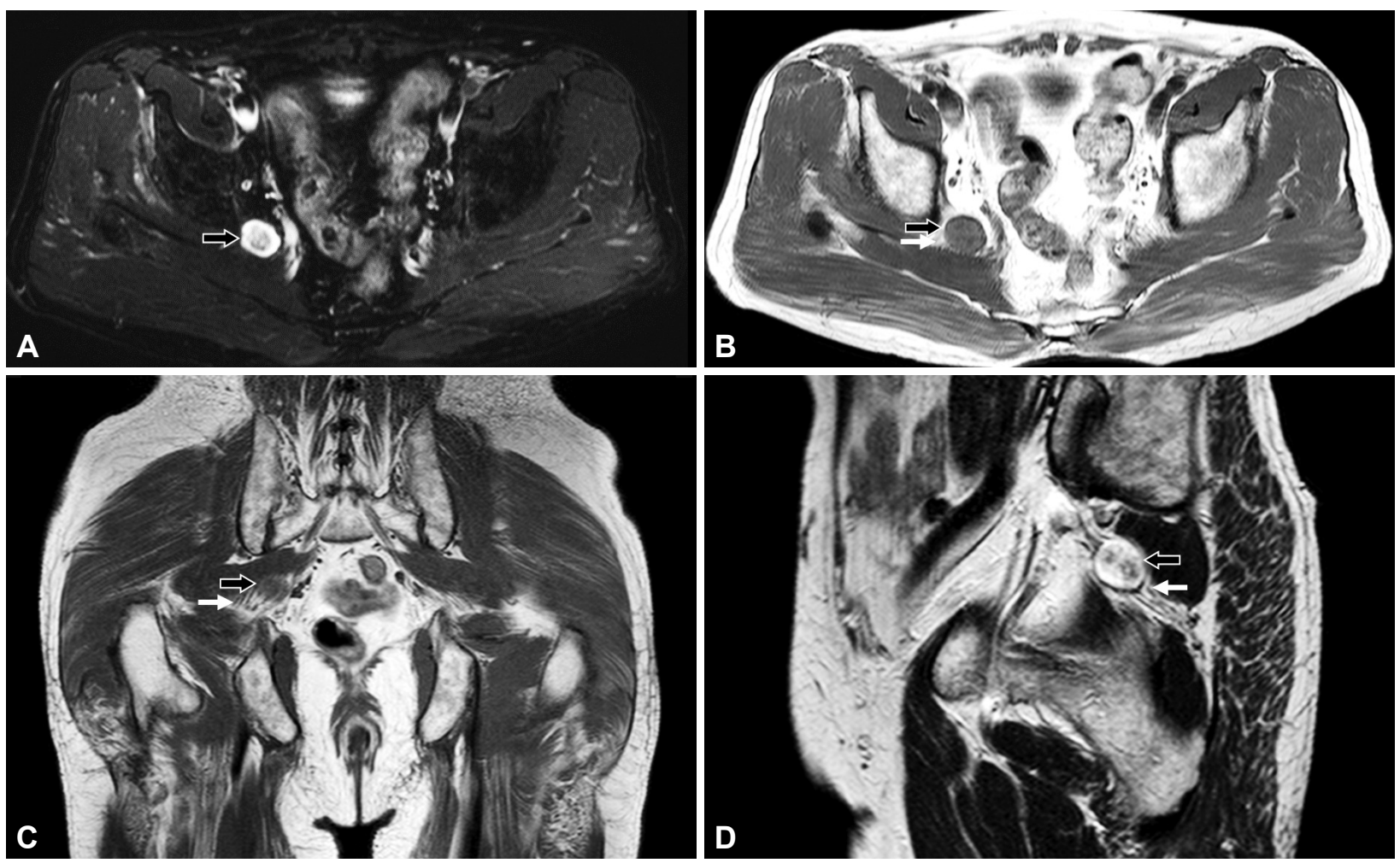

Figure 1. A nodular lesion (about $2.2 \mathrm{~cm}$ in diameter, black arrow) at the right greater sciatic notch region on hip magnetic resonance imaging. (A) Axial T2 spectral adiabatic inversion recovery. (B) Axial T1 TSE. (C) Coronal T1 TSE. (D) Sagittal T2 TSE sequences. White arrow indicates the sciatic nerve. TSE: turbo spin echo. 
(sciatica)을 유발하는 척추관 협착증, 요추추간판탈출증, 혹 은 후관절증후군 등과 같이 비교적 임상에서 흔한 다른 질 환들로 오인되어 감별이 늦어지는 경우가 많다. ${ }^{6}$ 따라서 정 확한 진단을 위해서는 신경전도검사, 근전도검사와 같은 전 기생리검사뿐 아니라 신경초음파, 전산화단층촬영 및 자기 공명영상검사 등 해부학적 구조를 확인할 수 있는 영상검사 가 필요하다.

말초신경병(peripheral neuropathy)에 기인한 이차성 하 지불안증후군에 관한 다양한 연구들이 있지만, 대부분의 경 우 당뇨, 신부전, 갑상선저하증, 영양결핍 및 알코올중독 등 과 같은 대사성 말초신경병이나, 유전성 말초신경병, 그리고 탈수초성 말초신경병 등에 관련된 연구가 대부분이다. 이러 한 경우의 말초신경병은 비교적 전신적이고 대칭적인 다발 신경병(polyneuropathy)의 형태를 보이고, 하지불안증후군 의 발현과 관련된 병태생리적 기전은 주로 소섬유신경병 (small fiber neuropathy)과 같이 작은 신경다발의 손상을 원 인으로 추정하고 있다. 그러나 본 증례의 경우는 특이하게도 직경이 큰 단일 신경에 종양이 발생하여 신경을 압박하거나 자극해서 하지불안증후군을 유발하였을 것으로 추측된다. 압박되거나 자극된 신경 부위 주변에는 통증이 발생하는 것 이 일반적이지만 본 증례처럼 비교적 큰 단일신경이 압박되 어 포착신경병(entrapment neuropathy)이 발생하여 하지불 안증후군 증상이 나타난 보고들이 있었는데, 이는 복재신경 (saphenous nerve), 외측넙다리피부신경, 그리고 총비골신 경의 대퇴분지(crural branch of the common peroneal nerve) 등이었다. ${ }^{78}$ 유사한 사례로 수근관증후군에서 수지불안증후 군(restless hand syndrome)이 발생하였음이 보고되기도 하 였다. ${ }^{9}$ 따라서 드물지만 큰 신경의 압박이나 자극으로 인하여 하지불안증후군이 이차적으로 발생할 수 있을 것으로 생각 되며, 신경감압술이 일부의 포착신경병에서 하지불안증후 군의 증상 호전에 효과가 있었다는 최근의 연구 결과는 이 를 뒷받침할 수 있는 근거가 될 수 있을 것으로 추측한다. ${ }^{10}$

저자들이 본 증례의 환자에게 하지불안증후군을 진단한 후 약물치료를 하며 추적관찰을 하던 중, 약 1년 뒤 환자의 증상은 빈도나 강도 면에서 이전보다 악화되는 경과를 보였 다. 이는 환자의 하지불안증후군 자체가 악화된 것일 수 있지 만, 고관절 자기공명영상검사에서 궁둥신경의 종양이 발견 되었기 때문에 이와 관련한 궁둥신경병(sciatic neuropathy) 에 의한 증상일 가능성, 또는 두 가지 질환이 동시에 나타났을
가능성 또한 배제할 수 없을 것으로 생각된다. 한편 환자의 첫 증상이었던 우측 허벅지 부위의 감각저하는 종양의 침범 으로 인한 초기 증상이었을 가능성이 있지만, 요천추신경총 의 해부학적 주행을 고려할 때 외측넙다리피부신경 부위의 통증이나 감각저하의 원인을 완전하게 설명하기는 어렵다. 환자의 경우 상기의 감각증상에 대한 약물 반응이 좋은 편이 었고 경제적인 문제가 있어 추가 검사를 거부하였기 때문에 검사상의 오류 가능성을 포함, 정확한 원인 감별을 위한 추 적 전기생리검사를 시행하지 못했던 점은 현재까지 아쉬움 으로 남는다. 전형적인 하지불안증후군의 진단기준에 부합 하는 환자라고 할지라도 그 경과가 일반적인 경우와는 다르 고 이차성 원인을 완전히 배제하지 못하였다면, 하지의 구조 적 병변을 확인하기 위하여 자기공명영상검사 등의 검사가 필요할 수 있다. 궁둥신경의 종양이 원인으로 생각되는 이차 성 하지불안증후군의 증례는 국내는 물론 해외에서도 보고 된 바가 없기 때문에 저자들은 본 증례를 문헌 고찰과 함께 보고하는 바이다.

\section{REFERENCES}

1. Allen RP, Picchietti D, Hening WA, Trenkwalder C, Walters AS, Montplaisi J. Restless legs syndrome: diagnostic criteria, special considerations, and epidemiology. A report from the restless legs syndrome diagnosis and epidemiology workshop at the National Institutes of Health. Sleep Med 2003;4:101-119.

2. Do JY, Yoon CH, Kim WJ, Yang KI, Park SH, Chu MK. Prevalence of restless legs syndrome in Korean adult population: comparison between International Restless Legs Syndrome Study Group criteria and Cambridge-Hopkins Diagnostic Questionnaire. J Korean Sleep Res Soc 2013;10:7-14.

3. Ondo W, Jankovic J. Restless legs syndrome: clinicoetiologic correlates. Neurology 1996;47:1435-1441.

4. Trotti LM. Restless legs syndrome and Sleep-Related Movement Disorders. Continuum (Minneap Minn) 2017;23(4, Sleep Neurology):1005-1016.

5. Kumar S, Ralli M, Sharma J, Sansanwal P, Singh G. Sciatic schwannoma: a rare entity. Clinical Cancer Investigation Journal 2015;4:720-722.

6. Mansukhani SA, Butala RR, Shetty SH, Khedekar RG. Sciatic nerve schwannoma: a case report. J Orthop Surg (Hong Kong) 2015;23:259-261.

7. Lewis F. The role of the saphenous nerve in insomnia: a proposed etiology of restless legs syndrome. Med Hypotheses 1991;34:331-333.

8. Crotti FM, Carai A, Carai M, Sgaramella E, Sias W. Entrapment of crural branches of the common peroneal nerve. Acta Neurochir Suppl 2005;92:69-70.

9. Tan EK, Koh KK, Arulanandam S, Lo YL. Restless hand symptoms in carpal tunnel syndrome. Int J Clin Pract 2004;58:1000-1002.

10. Anderson JC, Fritz ML, Benson JM, Tracy BL. Nerve decompression and restless legs syndrome: a retrospective analysis. Front Neurol 2017; $8: 287$. 